\title{
Review Article \\ Role of Bile Acids in Dysbiosis and Treatment of Nonalcoholic Fatty Liver Disease
}

\author{
Caihua Wang $\mathbb{D}^{1},{ }^{1}$ Chunpeng Zhu $\mathbb{D},{ }^{1}$ Liming Shao $\mathbb{D},{ }^{1}$ Jun Ye $\mathbb{D},{ }^{1}$ Yimin Shen $\mathbb{D},{ }^{2}$ \\ and Yuezhong Ren $\mathbb{1}^{2}$ \\ ${ }^{1}$ Department of Gastroenterology, The Second Affiliated Hospital, College of Medicine, Zhejiang University, Hangzhou 310009, China \\ ${ }^{2}$ Department of Endocrinology and Metabolism, The Second Affiliated Hospital, College of Medicine, Zhejiang University, \\ Hangzhou 310009, China
}

Correspondence should be addressed to Yuezhong Ren; renyuez@zju.edu.cn

Received 11 April 2019; Revised 21 May 2019; Accepted 30 May 2019; Published 24 June 2019

Academic Editor: Michele T. Pritchard

Copyright () 2019 Caihua Wang et al. This is an open access article distributed under the Creative Commons Attribution License, which permits unrestricted use, distribution, and reproduction in any medium, provided the original work is properly cited.

\begin{abstract}
Nonalcoholic fatty liver disease (NAFLD) is a major health threat around the world and is characterized by dysbiosis. Primary bile acids are synthesized in the liver and converted into secondary bile acids by gut microbiota. Recent studies support the role of bile acids in modulating dysbiosis and NAFLD, while the mechanisms are not well elucidated. Dysbiosis may alter the size and the composition of the bile acid pool, resulting in reduced signaling of bile acid receptors such as farnesoid X receptor (FXR) and Takeda G protein-coupled receptor 5 (TGR5). These receptors are essential in lipid and glucose metabolism, and impaired bile acid signaling may cause NAFLD. Bile acids also reciprocally regulate the gut microbiota directly via antibacterial activity and indirectly via FXR. Therefore, bile acid signaling is closely linked to dysbiosis and NAFLD. During the past decade, stimulation of bile acid receptors with their agonists has been extensively explored for the treatment of NAFLD in both animal models and clinical trials. Early evidence has suggested the potential of bile acid receptor agonists in NAFLD management, but their longterm safety and effectiveness need further clarification.
\end{abstract}

\section{Introduction}

Nonalcoholic fatty liver disease (NAFLD) is emerging as the leading cause of chronic liver disease worldwide. It is diagnosed when fat is more than $5 \%$ of the weight of the liver. It affects $10-40 \%$ of the adult population worldwide and 30 $40 \%$ of adults in the US [1]. Researchers have also found that $40-80 \%$ of type 2 diabetic patients and $30-90 \%$ of the obese population have NFALD [2]. NAFLD encompasses a spectrum of liver pathologies, ranging from simple fatty liver (steatosis) to nonalcoholic steatohepatitis (NASH), cirrhosis, and hepatocellular carcinoma in patients without a history of alcoholism. It can affect people of any age and any ethnicity. However, Hispanics and Asians are at higher risk for the disease [3]. It is estimated that approximately $20 \%$ of patients in the US with NAFLD have NASH [4]. A subset of NAFLD patients will evolve to cirrhosis and hepatocellular carcinoma. In addition to liver-related morbidity and mortality,
NAFLD has been independently associated with extrahepatic diseases such as type 2 diabetes mellitus, cardiovascular diseases, and chronic kidney diseases [5]. Besides, NAFLD may add increased risk for extrahepatic cancers, especially in the gastrointestinal tract [6]. Furthermore, NAFLD has been closely associated with dysbiosis, the imbalance in the gut microbiota [7].

It has been estimated that human gut microbiota is composed of 300-500 species with a total of $10^{13}$ to $10^{14}$ bacteria. The collective genome ("microbiome") encodes at least 100 times as many genes as the human genome. The stomach and small intestine have only a few species of bacteria, while the large intestine contains high densities and varieties of living bacteria, reaching concentrations of up to $10^{11}$ or $10^{12}$ cells/g of luminal tissues [8]. In a healthy human, host and bacterial colonizers maintain a homeostasis that benefits both parties. The host provides an environment and source of nutrients for the microbiota. On the other hand, the gut 
microbiota is crucial for the synthesis of essential amino acids and vitamins and the breakdown of indigestible components in the diet such as plant polysaccharides [9]. In general, dysbiosis can be categorized into three types: loss of beneficial bacteria, the expansion of harmful bacteria, and a general loss of diversity of bacteria [10]. The three types of dysbiosis are not mutually exclusive and can occur simultaneously in the same host. In addition to NAFLD, dysbiosis has been implicated in a plethora of diseases including inflammatory bowel disease, metabolic disorders, obesity, type 2 diabetes, and colorectal cancer. During the past decade, many studies support that dysbiosis and NAFLD are closely related to malfunction in bile acid signaling [11].

Bile acids are essential molecules in fat absorption [12]. Bile acids are produced by hepatocytes via oxidation of cholesterol in a multistep process to form the primary bile acids, such as cholic acid and chenodeoxycholic acid. They are synthesized via the classical pathway and the alternative pathway, with the classical pathway accounting for at least $75 \%$ of the products [13]. In hepatocytes, primary bile acids are further conjugated to glycine or taurine to form conjugated bile acids. Conjugating bile acids have pKa values between 1 and 4 which make them watersoluble when entering into the duodenum with a $\mathrm{pH}$ between 3 and 5 and allow them to perform their physiologic function of emulsifying and solubilizing fats [14]. Bile acids are secreted into the bile canaliculi via the bile salt export pump. Then, bile with the newly formed bile acids is transported through a system of the biliary tree to the gallbladder, where it is stored and concentrated during an empty stomach. Upon food consumption, the bile is released into the duodenum following gallbladder contraction in response to cholecystokinin produced by enteroendocrine I cells [15]. The intestinal microbiota converts primary bile acids into secondary bile acids such as deoxycholic acid, lithocholic acid, and ursodeoxycholic acid [16]. Approximately 95\% of bile acids are actively reabsorbed in the distal ileum by the enterocytes and transported to the liver through the portal vein, while the remaining $5 \%$ is deconjugated by the gut microbiota and excreted in the feces. However, a small fraction of bile acids escapes hepatic uptake, flows into the systemic circulation, and reaches the peripheral tissues where they exert peripheral effects [15].

In addition to their role in fat absorption, bile acids are also signaling molecules and regulate glucose and lipid metabolism through activation of the farnesoid $\mathrm{X}$ receptor (FXR), a multipurpose nuclear receptor, and the Takeda G protein-coupled receptor 5 (TGR5). Impaired bile acid signaling was reported in patients with NAFLD and dysbiosis [17]. On the other hand, improved bile acid signaling via bile diversion altered the profile of gut microbiota and regulated glucose and lipid homeostasis, resulting in improved metabolic phenotype [18]. The goal of this review article is to summarize the existing literature on the role of bile acid signaling in dysbiosis and pathogenesis of NAFLD, as well as the application of bile acid receptor agonists in the treatment of NAFLD from animal models to clinical trials.

\section{Dysbiosis}

Despite the wide microbial diversity between adults, Bacteroidetes, Firmicutes, Proteobacteria, and Actinobacteria are the only 4 predominant phyla in the gut microbiota, with Bacteroidetes and Firmicutes occupying more than 95\% of the phylogenetic types [19]. Some Firmicutes are butyrate producers in the colon and essential in colonic health in humans [20]. In contrast, Bacteroidetes have large numbers of genes encoding for carbohydrate active enzymes such as eliminases, glycosyltransferases, and glycoside hydrolases. This allows them to utilize a variety of energy sources in the gut depending on availability, by selective mechanisms to control gene expression [21]. Bacteroidetes are also the phylum with the greatest number of producers for B group vitamins [22]. On the other hand, Escherichia coli (E. coli), a species of bacteria from the family Enterobacteriaceae which belongs to the phylum Proteobacteria, can generate vitamin K2 to benefit the host [23].

Dysbiosis is defined as microbial imbalance or maladaptation on or inside the body. By comparing distal gut microbiota of genetically obese and lean mice, it has been demonstrated that obesity is associated with a decrease in Bacteroidetes and an increase in Firmicutes, resulting in the increased capacity to harvest energy from the diet. Colonization of germ-free mice with microbiota from genetically obese mice led to a significant increase in body fat than that from lean mice [24]. Obese mice induced by a fat-rich Western diet had a lower Bacteroidetes/Firmicutes ratio in distal gut microbiota [25]. Similarly, obese people displayed a decreased ratio of Bacteroidetes/Firmicutes, which was reverted after diet [26]. Additionally, obese rats induced by a fat-rich Western diet had the expansion of Bilophila wadsworthia in the intestine. This bacterial bloom promoted hepatic conjugation of bile acids, from glycocholic to taurocholic acid, resulting in solubilizing the hydrophobic fat in the diet and delivery of taurine-derived sulfur to the distal bowel [27].

\section{Reciprocal Regulation between Bile Acids and Dysbiosis}

Intestinal microbiota is known to regulate bile acid homeostasis via biotransformation such as deconjugation, dehydroxylation, oxidation, and desulfation. In terms of deconjugation, bacterial genera such as Bacteroides, Lactobacillus, Bifidobacterium, Clostridium, and Listeria produce bile salt hydrolases (BSHs), which deconjugate taurine and glycine groups in the primary bile acids produced in the liver [16]. In germ-free or antibiotic-treated rats, the deconjugation of taurine by gut bacteria was blocked, shifting the balance to almost exclusively taurine-conjugated bile acids, which resulted in increased taurine-conjugated bile acids in the liver, heart, and kidney [28]. Mice colonized with BSH-deleted Bacteroides thetaiotaomicron displayed a high level of taurineconjugated bile acids and altered metabolism including decreased weight gain and respiratory exchange ratios, as well as changes in immune pathways in the gut and liver [29]. For dehydroxylation, Clostridium and Eubacterium of 
the Firmicutes phylum generate bile acid $7 \alpha$-dehydroxylase, which converts primary bile acids (cholic acid and chenodeoxycholic acid) into secondary bile acids (deoxycholic acid, lithocholic acid, and ursodeoxycholic acid) [30]. The $7 \alpha$-dehydroxylation occurs after deconjugation and is the most physiologically significant conversion of bile acids in humans. In a gnotobiotic mouse model, intestinal bile acid $7 \alpha$-dehydroxylation by Clostridium scindens has been associated with protection again Clostridium difficile infection [31]. With regard to oxidation, the bacterial genera such as Bacteroides, Clostridium, Eubacterium, Escherichia, Eggerthella, Peptostreptococcus, and Ruminococcus generate bile acid hydroxysteroid dehydrogenases (HSDHs) which convert toxic bile acids into ursodeoxycholic acid, which is less toxic to human cells and more water-soluble [32]. Finally, several gut bacteria such as Clostridium sp. Strain S2 produce sulfatases which are able to increase the desulfation of bile acids [33]. Desulfation of bile acids by gut bacteria facilitates bile acid reabsorption [34] and is essential for the homeostasis of the bile acid pool [34].

On the other hand, bile acids are the most significant endogenous metabolites correlating with dysbiosis [35]. When taurocholic acid, but not glycocholic acid, was added to mice fed with a low-fat diet, it promoted the expansion of Bilophila wadsworthia and resulted in colitis in genetically susceptible IL-10 knockout mice [36]. In patients with cirrhosis, the chenodeoxycholic level was positively correlated with the abundance of fecal Enterobacteriaceae while the deoxycholic acid level was positively correlated with Ruminococcaceae [37]. Islam et al. reported that when rats were fed with diets supplemented with cholic acid, they induced phylum-level alterations in the composition of the gut microbiota with a decrease in Bacteroidetes and an increase in Firmicutes similar to those induced by high-fat diets [38]. Clements et al. showed that biliary obstruction, which reduced the level of intraluminal bile acids, increased the Gram-negative aerobic population and induced bacterial translocation in the intestine [39]. On the other hand, administration of conjugated bile acids to cirrhotic rats elevated bile acid secretion, inhibited intestinal bacterial overgrowth, and reduced bacterial translocation [40].

Bile acids have both direct influences on gut microbiota and indirect influences mediated by FXR. It has been demonstrated that deoxycholic acid is an order of magnitude greater than cholic acid in antibacterial activity $[16,41]$. In addition, unconjugated bile acids possess more potent antibacterial action than conjugated counterparts via membrane disruption and leakage of cellular contents [35]. Sung et al. demonstrated that hydrophobic bile acids (taurodeoxycholic acid and deoxycholic acid) had more significant inhibition on the growth of bacteria when compared with the hydrophilic bile acids (taurocholic acid, chenodeoxycholic acid, and tauroursodeoxycholic acid) [42]. Moreover, bile acids may induce the expression of stress response genes in gut bacteria in response to membrane perturbation, oxidative stress, and DNA damage [43]. In terms of FXR involvement, Inagaki et al. reported that FXR agonist GW4064 inhibited bacterial overgrowth and mucosal injury in the small intestine caused by biliary obstruction by inducing the expression of Ang1, $i$ Nos, and IL-18 [44]. Zheng et al. showed that a high-fat diet elevated intestinal bile acid pool within $12 \mathrm{~h}$, followed by a change in gut microbiota at $24 \mathrm{~h}$, indicating that bile acids might regulate the composition of gut microbiota. Feeding mice with a normal diet supplemented with taurocholic acid and glycocholic acid also expanded the bile acid pool, especially for secondary bile acids, and increased the abundance of Verrucomicrobia compared with the normal diet. However, the use of the FXR agonist GW4064 to inhibit bile acid biosynthesis prevented the development of the obese phenotype and the alteration of the gut microbiota, demonstrating that regulation of gut microbiota by bile acids is FXR dependent [45]. Bile acid receptor FXR knockout mice on a highfat diet had high levels of primary bile acids such as betamuricholic acid and tauro-beta-muricholic acid. The mice had elevated relative abundance of Firmicutes and decreased relative abundance of Bacteroidetes compared with wild-type mice on the same diet [46]. Furthermore, Pathak et al. demonstrated that the FXR agonist fexaramine induced lithocholic acid-producing bacteria Acetatifactor and Bacteroides, increased taurolithocholic acid, and elevated glucose tolerance [47].

\section{Bile Acid Signaling}

Bile acids bind and activate FXR in the order of chenodeoxycholic acid $>$ lithocholic acid $>$ deoxycholic acid $>$ cholic acid. On the other hand, the most efficacious bile acid ligands for TGR5 are in the order of lithocholicacid $>$ deoxycholic acid $>$ chenodeoxycholic acid $>$ cholic acid [48] Bile acids are modulators for lipid and glucose metabolism which is mediated mainly by FXR and TGR5 [49]. Bile acids reduce triglyceride levels via a pathway involving FXR and the small heterodimer partner (SHP), as well as sterol regulatory element-binding protein 1 (SREBP-1), which targets lipogenic genes [50]. Activation of FXR also promotes the expression of the peroxisome proliferator-activated receptor alpha (PPARalpha), which is a nuclear receptor that regulates lipid metabolism, glucose homeostasis, and antiinflammatory activities [51]. Cariou et al. reported that mice with FXR gene knockout had impaired glucose tolerance and insulin resistance. The mice also displayed reduced adipose tissue mass and serum leptin levels as well as increased plasma-free fatty acid levels. The FXR agonist GW4064 promoted insulin signaling and insulin-stimulated glucose uptake in adipocytes. Furthermore, GW4064 treatment increased insulin resistance in genetically obese ob/ob mice in vivo [52]. In another study with FXR knockout mice, mice had increased free fatty acid levels and developed severe NAFLD [53]. Zhang et al. found that the FXR agonist GW4064 or hepatic overexpression of the FXR gene reduced blood glucose levels in both genetically diabetic $\mathrm{db} / \mathrm{db}$ and wild-type mice. Activation of FXR in $\mathrm{db} / \mathrm{db}$ mice increased hepatic glycogen synthesis and the glycogen level via enhancing insulin sensitivity [54]. On the other hand, bile acid signaling may also enhance insulin sensitivity and reduce obesity via activating TGR5. Brighton et al. reported that bile acids were bound with TGR5 on the basolateral L cell membrane and stimulated the release of glucagon-like 
peptide-1 (GLP-1), which is capable of increasing insulin release, lowering glucagon secretion from the pancreas, and reducing food intake and gastrointestinal motility [55]. Thomas et al. demonstrated that TGR5 overexpression enhanced GLP-1 release in vivo, which increased glucose tolerance and improved liver and pancreatic function. In addition, the TGR5 agonist induced GLP-1 release via elevating the intracellular ATP/ADP ratio and intracellular calcium mobilization in enteroendocrine L cells [56].

Bile acid signaling also controls bile acid levels. The physiological concentration of bile acids is regulated through FXR and TGR5, by inhibiting the expression of cytochrome P450 7A1 (CYP7A1), a rate-limiting enzyme in bile acid synthesis [57]. In the liver, FXR promotes the expression of SHP, an atypical nuclear receptor lacking a DNA binding domain. Then, SHP-1 inhibits the activity of liver receptor homolog 1 (LRH-1), an orphan nuclear receptor that positively regulates CYP7A1 expression via binding to a response element in the CYP7A1 promoter [57]. In the small intestine, FXR regulates bile acid levels via FGF15 in the mouse (FGF19 in human)/fibroblast growth factor receptor 4 (FGFR4)/ERK1/2 pathway, which inhibits bile acid synthesis by repressing transcription of CYP7A1 and prevents the accumulation of toxic bile acids in the liver [58]. Mice lacking FGF15 had increased hepatic CYP7A1 enzyme activity and fecal bile acid excretion [59]. Lou et al. found that TGR5 activation induced the expression of proinflammatory cytokines in Kupffer cells and suppressed the expression of CYP7A1 in murine hepatocytes [60]. These regulatory mechanisms contribute to the delicate bile acid feedback regulation.

\section{Evidences That Dysbiosis Links NAFLD}

Wigg et al. were the first to report the association between dysbiosis and NAFLD. They found that NAFLD patients had bacterial overgrowth in the small intestine and higher TNF- $\alpha$ levels compared with control subjects [61]. In a comparison study of intestinal microbiota among adults with biopsy-proven NAFLD and living liver donors as healthy controls, quantitative real-time polymerase chain reaction analysis of stool samples revealed that NAFLD patients had a lower percentage of Bacteroidetes compared to health controls [62]. Wong et al. reported that NAFLD patients displayed a decrease in Faecalibacterium (Firmicutes) and Anaerosporobacter (Firmicutes) but an increase in Parabacteroides (Bacteroidetes) and Allisonella (Firmicutes) in gut microbiota [63]. In obese patients with NAFLD, deep sequencing of the fecal microbiota showed overrepresentation of Lactobacillus and Lachnospiraceae and underrepresentation of Ruminococcaceae in the phylum Firmicutes [64]. Zhu et al. examined the composition of gut bacteria of NAFLD, obese, and healthy children by $16 \mathrm{~S}$ ribosomal RNA pyrosequencing. The representation of Escherichia with alcoholproducing capacity was similar between healthy and obese groups but was significantly increased in the NAFLD group. In addition, there was an increase in blood-ethanol concentration in children with NAFLD [65]. In another study of pediatric NAFLD patients, NAFLD progression was accom- panied by an increases in Ruminococcus (Firmicutes) and Dorea (Firmicutes) in gut microbiota, indicating an association between gut microbiota and disease severity [66].

Nevertheless, dysbiosis has also been related to metabolic diseases, since several studies supported that increased Firmicutes and decreased Bacteroidetes may lead to obesity $[24,67]$. In a prospective cross-sectional study examining the gut microbiota composition of 39 adults with biopsyproven NAFLD, Da Silva et al. found that NAFLD patients had a lower abundance of Ruminococcus, F. prausnitzii, and Coprococcus. Furthermore, this lower abundance of gut microbiota was independent of obesity and insulin resistance [68]. Le Roy et al. reported that when wild-type mice were fed with a high-fat diet, only mice that received fecal transplantation from NAFLD mice developed the disease [69]. Mouzaki et al. found that Bacteroidetes were less abundant in NAFLD patients compared with the control, after adjusting for body mass index and weight-adjusted calorie intake [70]. These findings reveal that dysbiosis contributes to the development of NAFLD independent of metabolic abnormality.

\section{Mechanisms Where Dysbiosis Is Involved in NAFLD}

Dysbiosis plays an essential part in the development of NAFLD. Proposed mechanisms in the relationship of dysbiosis and NAFLD include augmented capacity for energy extraction from food, increased intestinal permeability, elevated serum LPS, overgrowth of bacteria, decreased choline metabolism, and suppressed bile acid signaling. The following paragraphs will delineate the proposed mechanisms one by one.

One mechanism by which dysbiosis promotes NAFLD is an increased energy yield from food. ob/ob mice as well as obese humans have an altered composition of their gut microbiota and increased short-chain fatty acids [24]. Short-chain fatty acids contain 1-6 carbons and are the main product of bacterial fermentation of undigested dietary fiber, thus improving energy extraction from the diet [71]. Loss of Gpr41, a G protein-coupled receptor for short-chain fatty acids, is associated with reduced efficiency of energy harvest from the diet [72].

Secondly, elevated intestinal permeability is closely associated with NAFLD. The intestinal epithelial cells, a physical barrier between potential pathogens and the underlying lamina propria, are linked together through tight junctions and crucial for maintaining intestinal immune homeostasis. Dysbiosis can target various signal transduction pathways, regulate the expression and distribution of tight junction proteins, and increase intestinal permeability [73]. Elevated permeability leads to translocation of bacterial components that triggers the inflammatory response of the liver through TLR4 (receptor for LPS), TLR5 (receptor for bacterial flagellin), and TLR9 (receptor for bacterial DNA) [74]. In patients with NAFLD, both intestinal permeability and bacterial growth were increased and correlated with the severity of steatosis [75]. ob/ob mice had reduced mucosal barrier function, modified distribution of tight junction proteins, and 
higher levels of proinflammatory cytokines compared with lean control mice [76].

Thirdly, LPS is endotoxin derived from the outer membrane of Gram-negative bacteria. LPS is recognized by TLR4 and triggers inflammatory response through the TLR4/NF- $\kappa B$ signaling pathway [77]. Normally, only a small amount of LPS crosses the epithelial membrane, enters the portal system, and is degraded in the liver. In mice, dysbiosis induced by high-fat feeding increased plasma LPS levels, which activated TLR4 on Kupffer cells and hepatocytes, and initiated obesity and insulin resistance. In addition, LPS infusion in normal diet-fed mice produced a metabolic response similar to high-fat feeding [78]. In another study, inflammasome-deficiency mice developed NAFLD and were associated with increased levels of LPS in the portal vein and TNF- $\alpha$ expression. Cohoused wild-type mice with inflammasome-deficient mice developed NAFLD [79]. In a human study, Kapil et al. documented that patients with NAFLD had significantly higher LPS and TLR4 levels compared with patients without NAFLD [80]. In patients with NAFLD, Vespasiani-Gentilucci et al. found that the TLR4 expression was significantly elevated and was associated with the activation of fibrogenic cells and the degree of fibrosis [81]. In a prospective cohort study of 920 patients, Wong et al. reported that the levels of LPS-binding protein were significantly increased and were associated with the development of NAFLD [82].

Fourthly, many studies have also shown that small intestinal bacterial overgrowth (SIBO) is associated with NAFLD. In a study of 372 eligible patients who were tested for SIBO and had liver imaging, 141 (37.9\%) were tested positive for SIBO and 231 (62.1\%) were negative. NAFLD occurred in $45.4 \%$ (64/141) of the SIBO-positive group, while only $17.3 \%(40 / 231)$ in the negative group [83]. Kapil et al. reported that 12 out of 32 patients with NAFLD had SIBO with Escherichia coli as the predominant bacterium. Patients with SIBO had significantly higher levels of LPS, CD14 mRNA, NF- $\kappa$ B mRNA, and TLR4 protein compared with those without SIBO [80]. Sabate et al. documented that the frequency of positive SIBO was higher in obese patients $(24 / 136,17.1 \%)$ than in healthy subjects $(1 / 40,2.5 \%)$. In a multivariate analysis, SIBO was an independent factor of NAFLD [84]. Shanab et al. found that NAFLD patients had a higher prevalence of SIBO $(77.78 \%$ vs. $31.25 \%)$, which was associated with the enhanced expression of TLR4 and IL-8 [85]. In a study of 125 obese children, 47 (37.6\%) had intestinal dysbiosis and 47 (37.6\%) were SIBO positive compared with $3.3 \%$ positive in the controls. NAFLD was present in 28/47 (59.5\%) of the SIBO-positive obese group, compared with only $8 / 78(10.2 \%)$ of the SIBO-negative obese group and $0 / 120(0 \%)$ of the controls. Obese children with SIBO positivity had higher rates of abnormality in liver function [86].

Fifthly, choline is an essential nutrient and a main methyl donor in the physiological processes. Mice with a methionine- and choline-deficient diet have been shown to develop NAFLD with inflammasome activation, IL- $1 \beta$ secretion, and liver inflammation [87]. Phosphatidylcholine, an important choline metabolite in the liver, is required for VLDL secretion, which is a mechanism to dispose excessive fat accumu- lation in the liver [88]. In patients requiring long-term parenteral nutrition, choline deficiency was reported to cause NAFLD, which was reversed with choline supplementation [89]. Deletion of betaine-homocysteine S-methyltransferase in mice reduced choline levels in the tissue, resulting in fatty liver and hepatocellular carcinomas [90]. In a study of 15 female subjects on well-controlled diets, Spencer et al. found that choline deficiency resulted in the development of fatty liver. Additionally, Gammaproteobacteria was negatively correlated with fat accumulation in the liver, while Erysipelotrichi had a positive correlation [91]. Mouse strain 129 S6 with a high-fat diet, known to be susceptible to NAFLD, had a low plasma level of phosphatidylcholine and high urinary excretion of methylamines. Conversion of choline into methylamines by microbiota in strain 129 S6 reduced the bioavailability of choline and mimicked the effect of cholinedeficient diets [92].

Finally, impaired bile acid signaling is probably the most important mechanism for NAFLD development. By binding to the FXR and TGR5, bile acids were reported to increase insulin sensitivity and decrease hepatic gluconeogenesis and circulating triglycerides [93]. Yang et al. found that patients with NAFLD had lower levels of hepatic FXR and elevated levels of SREBP-1C and triglyceride, while there was no change in SHP expression [94]. Dasarathy et al. reported that patients with NAFLD had elevated fasting plasma bile acids [95]. In patients with NAFLD, Jiao et al. reported that serum levels of primary and secondary bile acids were elevated. Gut microbiota had increased abundance in Escherichia and Bilophila, which metabolize taurine and glycine, indicating increased production of secondary bile acids. Proportion for deoxycholic acid (secondary) was increased, while the proportion for chenodeoxycholic acid (primary) was decreased in the bile acid pool. The expression of SHP was not changed in the livers, while the downstream effector gene CYP7A1 was elevated. Furthermore, serum FGF19 levels were decreased, indicating impaired FXR signaling in NAFLD [17]. Mouzaki et al. found that bile aid synthesis was higher in patients with NAFLD compared with the control. Bacteroidetes and Clostridium leptum counts were less abundant in NAFLD patients compared with the control, after adjusting for body mass index and weightadjusted calorie intake [70]. FXR is also responsible for the beneficial effects of bariatric surgery, which is associated with improvements in type- 2 diabetes and NAFLD. In mice with diet-induced obesity, bariatric surgery elevated circulating bile acids and altered gut microbiota. In the absence of bile acid signaling (FXR knockout mice), the effectiveness of bariatric surgery in weight loss and elevated glucose tolerance was significantly decreased [96]. Parseus et al. reported that FXR-deficient mice had a significantly higher proportion of tauro-beta-muricholic acid compared with wild-type mice, suggesting reduced capacity to deconjugate bile acids. FXR-deficient mice showed mild NAFLD even in the presence of gut microbiota, suggesting that dysbiosis-induced NAFLD is FXR dependent [46]. Of note, the adverse reactions of FXR agonists were also observed in a clinical trial. The major adverse events 
were pruritus, which was found in $23 \%$ of the OCAtreatment group and increased the serum low-density lipoprotein cholesterol level in the clinical trial [97].

\section{Bile Acid Receptor Agonists for NAFLD in Animal Studies}

Many studies have been conducted so far to study the effectiveness of bile acid receptor agonists in animal models of NAFLD (Table 1). In a mouse model of NAFLD, McMahan et al. reported that treatment of genetically obese $\mathrm{db} / \mathrm{db}$ mice with dual bile acid FXR/TGR5 receptor agonist INT-767 reduced hepatic expression of profibrotic/proinflammatory genes and ameliorated the histological features of NAFLD. The treatment increased the anti-inflammatory Ly6C (low) phenotype of intrahepatic monocytes and elevated M2 phenotype of intrahepatic macrophages. Furthermore, treatment of monocytes with INT-767 in vitro increased the antiinflammatory IL-10 level through a cAMP-dependent pathway [98]. Roth et al. compared the effectiveness of INT-767 in a diet-induced ob/ob mouse model of NAFLD with FXR agonist obeticholic acid (OCA). They found that INT-767 exerted greater therapeutic potency and efficacy than OCA in improving NAFLD histology [99]. To elucidate the relative importance of FXR versus TGR5 in mediating the effects of INT-767, Jadhav et al. used mice with FXR, TGR5, or SHP gene knockout to study NAFLD development. They found that INT-767 reversed obesity, hypercholesterolemia, and NAFLD by activation of FXR and/or TGR5. The results indicated that dual activation of FXR and TGR5 is an attractive strategy for treatment of NAFLD and metabolic disorders [100]. In a rat model of NAFLD, Hu et al. found that INT767 treatment significantly reduced hepatic lipid accumulation and infiltration of immune cells. INT-767 also corrected abnormal lipid metabolism and insulin resistance. Furthermore, levels for endotoxin, TNF- $\alpha$, and NF- $\kappa$ B were significantly reduced after INT-767 treatment [101]. In a rabbit model of high-fat diet-induced NAFLD and metabolic syndrome, Comeglio et al. found that long-term treatment with INT-767 ameliorated visceral adipose tissue accumulation, hypercholesterolemia, and NAFLD. INT-767 also alleviated insulin resistance and induced mitochondrial function, resulting in preadipocyte differentiation toward a metabolically healthy phenotype [102].

$\mathrm{Ma}$ et al. discovered that treatment with the FXR agonist GW4064 reduced weight gain in mice fed with a high-fat diet. GW4064 significantly lowered triglyceride and free fatty acid levels in the liver and attenuated NAFLD. GW4064 treatment also alleviated hepatic inflammation while having no effect on white adipose tissue. In addition, GW4064 decreased hyperinsulinemia and hyperglycemia through reducing mRNA levels of phosphoenolpyruvate carboxykinase and glucose-6-phosphatase, two key enzymes in gluconeogenesis [103]. de Oliveira et al. evaluated the effectiveness of selective bile acid receptor agonists INT747 (FXR) and INT777 (TGR5) to treat metabolic abnormality in mice induced by ovariectomy and high-fat diet. INT747 or INT777 treatment attenuated bodyweight gain and increased energy expenditure. Both treatments alleviated liver steatosis and normalized liver triglyceride and cholesterol content. Gene expression for liver acyl-CoA oxidase and carnitine palmitoyltransferase $1 \alpha$ was induced after INT747 and INT777 treatment, indicating increased fatty acid oxidation [104]. Haczeyni et al. showed that OCA improved adipose morphology, inflammation, and NAFLD in dietary but not metabolic obesity in mice [105]. Liles et al. demonstrated that the FXR agonist GS-9674 reduced serum transaminases, liver fibrosis, and steatosis in highfat, cholesterol, and sugar diet-induced mouse NAFLD [106]. In another mice model of NAFLD induced by a high-fat diet, Zheng et al. discovered that treatment with altenusin (2076A), a natural FXR agonist, reduced fat mass and glucose level. Altenusin treatment also reversed hepatic lipid droplet accumulation and steatosis. These effects were lost in FXR knockout mice. Mechanistically, increased insulin sensitivity and suppression of genes for hepatic gluconeogenesis and lipogenesis may account for the metabolic benefits of altenusin [107]. Zhang et al. examined the effects of WAY-362450 (W450), a highly selective and potent FXR agonist, on a mouse model of NAFLD induced by a methionine- and choline-deficient diet. WAY-362450 treatment decreased enzymes of liver damage, infiltration of inflammatory cells, and hepatic fibrosis, which was correlated with a reduction in hepatic fibrosis markers. The effect was FXR dependent since the protection was lost in FXR-deficient mice [108]. Carino et al. found that C57BL/6 mice were insulin resistant and developed NAFLD after 18 weeks on a high-fat diet. The NAFLD features included severe steatohepatitis and fibrosis, increased hepatic triacylglycerol and cholesterol, and abnormal expression of SREPB1c, FAS, ApoC2, $\operatorname{PPAR} \alpha$ and $\operatorname{PPAR} \gamma, \alpha$-SMA, $\alpha 1$ collagen, and MCP1 mRNAs. Treatment with BAR502, a dual agonist for FXR and TGR5, alleviated liver steatosis, inflammation, fibrosis, and abnormalities of the mRNAs. Furthermore, BAR502 improved adipose function with browning of white fat tissue [109]. The same group also discovered that both wild-type and TGR5 knockout mice fed with a high-fat diet developed NAFLD. Treating NAFLD mice with BAR501, a selective TGR5 receptor agonist, ameliorated insulin resistance and histology of NAFLD, while the effects were absent in TGR5 knockout mice [110]. Jin et al. reported that avermectin analogues, which are existing antiparasitic drugs, were partial agonists for FXR and had therapeutic effects for NAFLD. In mice with a high-fat diet, avermectin analogues decreased hepatic lipid accumulation, lowered serum cholesterol and glucose levels, and restored insulin sensitivity in a FXR-dependent manner [111].

\section{Bile Acid Receptor Agonists for NAFLD in Clinical Trials}

At present, there are no approved effective pharmacologic agents available for the management of NAFLD. The current treatment options include lifestyle change, weight loss, and probiotics. In a previous clinical trial, it has been shown that ursodeoxycholic acid, a weak bile acid receptor agonist, was ineffective in alleviating the degree of steatosis, 
TABLE 1: Bile acid receptor agonists for NAFLD in animal studies.

\begin{tabular}{|c|c|c|c|}
\hline References & Model & $\begin{array}{l}\text { Agent, mechanism, and } \\
\text { duration }\end{array}$ & Findings \\
\hline $\begin{array}{l}\text { McMahan } \\
\text { et al. [98] }\end{array}$ & Obese $\mathrm{db} / \mathrm{db}$ mice with NAFLD & $\begin{array}{l}\text { INT-767, dual } \\
\text { FXR/TGR5 agonist, } \\
6 \text { weeks }\end{array}$ & $\begin{array}{l}\text { (1) Improved the histological features of NAFLD } \\
\text { (2) Increased the proportion of intrahepatic monocytes } \\
\text { with the anti-inflammatory phenotype }\end{array}$ \\
\hline $\begin{array}{l}\text { Roth et al. } \\
\text { [99] }\end{array}$ & ob/ob mice with NAFLD & $\begin{array}{l}\text { INT-767, dual } \\
\text { FXR/TGR5 agonist, } \\
6 \text { weeks }\end{array}$ & $\begin{array}{l}\text { (1) Improved the histological features of NAFLD } \\
\text { (2) Reduced liver fibrosis, inflammation, and hepatocyte } \\
\text { lipid droplet area }\end{array}$ \\
\hline $\begin{array}{l}\text { Jadhav et al. } \\
\text { [100] }\end{array}$ & $\begin{array}{l}\text { TGR5, FXR, Apoe, and SHP knockout } \\
\text { mice with diet-induced NAFLD }\end{array}$ & $\begin{array}{l}\text { INT-767, dual } \\
\text { FXR/TGR5 agonist, } \\
12 \text { weeks }\end{array}$ & $\begin{array}{l}\text { (1) Reversed atherosclerosis and NAFLD } \\
\text { (2) Reduced high-fat diet-induced obesity dependent on } \\
\text { activation of both TGR5 and FXR }\end{array}$ \\
\hline $\begin{array}{l}\text { Hu et al. } \\
{[101]}\end{array}$ & High-fat diet-induced rat NAFLD & $\begin{array}{l}\text { INT-767, dual } \\
\text { FXR/TGR5 agonist, } \\
\text { 4 weeks }\end{array}$ & $\begin{array}{l}\text { (1) Reduced lipid accumulation and hepatic infiltration of } \\
\text { immune cells } \\
\text { (2) Restored lipid and glucose metabolism }\end{array}$ \\
\hline $\begin{array}{l}\text { Comeglio } \\
\text { et al. [102] }\end{array}$ & $\begin{array}{l}\text { High-fat diet-induced rabbit } \\
\text { metabolic syndrome }\end{array}$ & $\begin{array}{l}\text { INT-767, dual } \\
\text { FXR/TGR5 agonist, } \\
12 \text { weeks }\end{array}$ & $\begin{array}{l}\text { (1) Alleviated NAFLD and fat alterations } \\
\text { (2) Restored insulin sensitivity and induced preadipocytes } \\
\text { toward a metabolically healthy phenotype }\end{array}$ \\
\hline $\begin{array}{l}\text { Ma et al. } \\
{[103]}\end{array}$ & High-fat diet-induced mouse NAFLD & $\begin{array}{l}\text { GW4064, FXR agonist, } \\
6 \text { weeks }\end{array}$ & $\begin{array}{l}\text { (1) Ameliorated NAFLD and liver inflammation } \\
\text { (2) Reversed diet-induced hyperinsulinemia and } \\
\text { hyperglycemia }\end{array}$ \\
\hline $\begin{array}{l}\text { de Oliveira } \\
\text { et al. [104] }\end{array}$ & $\begin{array}{l}\text { Ovariectomized and high-fat } \\
\text { diet-induced mouse NAFLD }\end{array}$ & $\begin{array}{l}\text { OCA (FXR) and INT- } \\
777 \text { (TGR5), } 4 \text { weeks }\end{array}$ & $\begin{array}{l}\text { (1) Corrected NAFLD and metabolic changes } \\
\text { (2) Elevated energy expenditure and expression of key } \\
\text { metabolic genes }\end{array}$ \\
\hline $\begin{array}{l}\text { Haczeyni } \\
\text { et al. [105] }\end{array}$ & $\begin{array}{l}\text { Dietary and metabolic obesity } \\
\text { mouse NAFLD }\end{array}$ & OCA, 24 weeks & $\begin{array}{l}\text { Improved glucose tolerance and NAFLD in dietary but not } \\
\text { metabolic obesity mouse }\end{array}$ \\
\hline $\begin{array}{l}\text { Liles et al. } \\
{[106]}\end{array}$ & $\begin{array}{l}\text { High-fat, cholesterol, and sugar } \\
\text { diet-induced mouse NAFLD }\end{array}$ & $\begin{array}{l}\text { GS-9674, FXR agonist, } \\
90 \text { days }\end{array}$ & $\begin{array}{l}\text { (1) Improved the histological features of NAFLD } \\
\text { (2) Decreased serum transaminases and liver fibrosis }\end{array}$ \\
\hline $\begin{array}{l}\text { Zheng et al. } \\
\text { [107] }\end{array}$ & High-fat diet-induced mouse NAFLD & $\begin{array}{l}\text { Altenusin, FXR agonist, } \\
\text { 3 weeks }\end{array}$ & $\begin{array}{l}\text { (1) Reversed NAFLD, alleviated dyslipidemia and insulin } \\
\text { resistance, and reduced body weight and fat mass } \\
\text { (2) No effect on FXR knockout mice }\end{array}$ \\
\hline $\begin{array}{l}\text { Zhang et al. } \\
\text { [108] }\end{array}$ & MCD diet-induced mouse NAFLD & $\begin{array}{l}\text { WAY-362450, FXR } \\
\text { agonist, } 4 \text { weeks }\end{array}$ & $\begin{array}{l}\text { (1) Reduced inflammatory cell infiltration and fibrosis } \\
\text { (2) Protection was lost in FXR knockout mice }\end{array}$ \\
\hline $\begin{array}{l}\text { Carino et al. } \\
{[109]}\end{array}$ & $\begin{array}{l}\text { High-fat/high-fructose diet-induced } \\
\text { NAFLD }\end{array}$ & $\begin{array}{l}\text { BAR502, dual } \\
\text { FXR/TGR5 agonist, } \\
\quad 8 \text { weeks }\end{array}$ & $\begin{array}{l}\text { (1) Alleviated NAFLD, increased insulin sensitivity, and } \\
\text { elevated circulating levels of HDL } \\
\text { (2) Improved browning of white fat tissue }\end{array}$ \\
\hline $\begin{array}{l}\text { Carino et al. } \\
{[110]}\end{array}$ & $\begin{array}{l}\text { High-fat/high-fructose diet-induced } \\
\text { NAFLD }\end{array}$ & $\begin{array}{l}\text { BAR501, TGR5 } \\
\text { agonist, } 9 \text { weeks }\end{array}$ & $\begin{array}{l}\text { (1) Reversed insulin resistance and NAFLD } \\
\text { (2) Promoted energy expenditure and the browning of } \\
\text { white fat tissue. Lost effect in TGR5 knockout mice }\end{array}$ \\
\hline $\begin{array}{l}\text { Jin et al. } \\
{[111]}\end{array}$ & High-fat diet-induced mouse NAFLD & $\begin{array}{l}\text { Avermectin, FXR } \\
\text { agonist, } 14 \text { days }\end{array}$ & $\begin{array}{l}\text { (1) Ameliorated NAFLD, reduced glucose levels, and } \\
\text { improved insulin sensitivity } \\
\text { (2) Protection was FXR dependent }\end{array}$ \\
\hline
\end{tabular}

NAFLD: nonalcoholic fatty liver disease; db/db: diabetic/diabetic; ob/ob: obese/obese; FXR: farnesoid X receptor; TGR5: Takeda G protein-coupled receptor 5; SHP: small heterodimer partner; MCD: methionine- and choline-deficient; OCA: obeticholic acid.

necroinflammation, or fibrosis in NAFLD patients compared with the placebo control [112].

During the past decade, several clinical trials have been conducted to test the safety and effectiveness of OCA, a FXR ligand with 100 times higher affinity than chenodeoxycholic acid, in the treatment of NAFLD (Table 2). In a double-blind, placebo-controlled phase 2 trial, treatment with OCA for 6 weeks in 41 patients with NAFLD and type 2 diabetes mellitus dose-dependently improved insulin sensitivity and decreased body weight compared with the placebo. The treatment also significantly reduced markers for liver fibrosis and enzymes for liver damage such as gamma-glutamyl transferase and alanine aminotransferase. In addition, serum levels of low-density lipoprotein and fibroblast growth factor 19 were significantly increased compared with the placebo. Furthermore, the treatment reduced endogenous bile acid levels and hepatic cholesterol $7 \alpha$-hydroxylase activity, indicating FXR activation [113]. In a double-blind, randomized, placebo-controlled phase $3 \mathrm{a}$ trial, treatment with OCA for 72 weeks in 141 patients with NAFLD significantly improved the histological characteristics of NAFLD, including hepatic steatosis, inflammation, hepatocyte ballooning, and fibrosis [97]. However, the treatment was associated with side effects which include pruritus, an increase in low-density lipoprotein, and a decrease in high-density lipoprotein [97]. The side effects on lipoproteins are explained by the fact that OCA 
TABLE 2: Clinical trials studying effects of bile acid receptor agonists in NAFLD.

\begin{tabular}{|c|c|c|c|c|}
\hline References & $\begin{array}{l}\text { Drug, dose, frequency, and } \\
\text { duration }\end{array}$ & Finding or objective & $\begin{array}{l}\text { Phase of } \\
\text { trial }\end{array}$ & Status \\
\hline $\begin{array}{l}\text { NCT00501592, } \\
\text { (Mudaliar et al. [113]) }\end{array}$ & $\begin{array}{l}\text { OCA; } 25 \mathrm{mg}, 50 \mathrm{mg} \text {, or } \\
\text { placebo; once daily; } 6 \text { weeks }\end{array}$ & $\begin{array}{l}\text { Finding: improved insulin sensitivity and reduced markers of } \\
\text { liver inflammation and fibrosis in patients with T2DM and } \\
\text { NAFLD }\end{array}$ & Phase 2 & Completed \\
\hline $\begin{array}{l}\text { NCT01265498 } \\
\text { (Neuschwander-Tetri } \\
\text { et al. [97]) }\end{array}$ & $\begin{array}{l}\text { OCA, } 25 \mathrm{mg} \text { or placebo, } \\
\text { once daily, } 72 \text { weeks }\end{array}$ & Finding: improved liver histology in noncirrhotic NAFLD & Phase 3 & Completed \\
\hline NCT02633956 & $\begin{array}{l}\text { OCA; } 5 \mathrm{mg}, 10 \mathrm{mg}, 25 \mathrm{mg} \\
\text { or placebo; once daily }\end{array}$ & $\begin{array}{l}\text { Objective: effects of OCA and atorvastatin treatment on } \\
\text { lipoprotein metabolism in NAFLD }\end{array}$ & Phase 2 & Completed \\
\hline NCT02548351 & $\begin{array}{l}\text { OCA; } 10 \mathrm{mg}, 25 \mathrm{mg} \text {, or } \\
\text { placebo; once daily }\end{array}$ & $\begin{array}{l}\text { Objective: histology and liver-related clinical outcomes in } \\
\text { patients with noncirrhotic NAFLD with liver fibrosis }\end{array}$ & Phase 3 & Ongoing \\
\hline NCT03439254 & $\begin{array}{l}\text { OCA; } 10 \mathrm{mg}, 25 \mathrm{mg} \text {, or } \\
\text { placebo; once daily }\end{array}$ & $\begin{array}{c}\text { Objective: liver histology in adults with compensated } \\
\text { cirrhosis due to NAFLD }\end{array}$ & Phase 3 & Ongoing \\
\hline NCT01999101 & $\begin{array}{l}\text { GS-9674 (Px-104), } 5 \mathrm{mg} \\
28 \text { days }\end{array}$ & $\begin{array}{l}\text { Objective: analysis of clinical chemistry, hematology, and } \\
\text { assessment of clinical signs and adverse events of Px-104 in } \\
\text { adult NAFLD patients }\end{array}$ & Phase 2 & Terminated \\
\hline $\begin{array}{l}\text { NCT02854605. } \\
\text { Abstract in The Liver } \\
\text { Meeting } 2018\end{array}$ & $\begin{array}{l}\text { GS-9674; } 30 \mathrm{mg}, 100 \mathrm{mg} \text {, or } \\
\text { placebo; once daily; } \\
24 \text { weeks }\end{array}$ & $\begin{array}{l}\text { Finding: decline in hepatic fat, improvement in liver } \\
\text { biochemistry tests, and reduction in bile acid synthesis }\end{array}$ & Phase 2 & Completed \\
\hline NCT02781584 & $\begin{array}{l}\text { GS-9674, } 30 \text { mg, once daily, } \\
12 \text { weeks }\end{array}$ & $\begin{array}{l}\text { Objective: treatment with GS- } 9674 \text {, selonsertib, and GS- } 0976 \\
\text { alone or in combination, in NAFLD patients with advanced } \\
\text { fibrosis }\end{array}$ & Phase 2 & Ongoing \\
\hline NCT02913105 & $\begin{array}{l}\text { LMB763, dose not revealed, } \\
\text { once daily, } 12 \text { weeks }\end{array}$ & $\begin{array}{l}\text { Objective: effects of LMB763 with respect to safety, } \\
\text { tolerability, and inflammation in patients with NAFLD }\end{array}$ & Phase 2 & Ongoing \\
\hline NCT02855164 & $\begin{array}{l}\text { LJN452 or placebo, dose } \\
\text { and frequency not revealed, } \\
12 \text { weeks }\end{array}$ & $\begin{array}{l}\text { Objective: effects of different doses of LJN452 with respect to } \\
\text { safety, tolerability, and on markers of liver inflammation in } \\
\text { patients with NAFLD }\end{array}$ & Phase 2 & Ongoing \\
\hline
\end{tabular}

OCA: obeticholic acid; T2DM: type 2 diabetes mellitus; NAFLD: nonalcoholic fatty liver disease.

increases the expression of cholesteryl ester transfer protein, which transfers cholesterol from the high-density lipoprotein to the very low-density lipoprotein and low-density lipoprotein [114]. However, the changes in lipoproteins were not identified in animal studies since mice and rats lack the cholesteryl ester transfer protein $[114,115]$. To further examine the effects of OCA on lipoproteins, a randomized, doubleblind, placebo-controlled phase 2 study, evaluating the effects of OCA and atorvastatin treatment on lipoprotein metabolism in subjects with NAFLD (ClinicalTrials.gov identifier: NCT02633956), has recently been completed and the findings will be available in the near future. A phase 3 study to determine the safety and efficacy of OCA in NAFLD patients is recruiting subjects around the world (NCT02548351). The main goal of this study is to compare the effect of OCA with placebo on liver histology and clinical outcomes in NAFLD patients with liver fibrosis. Another phase 3 study examining the efficacy and safety of OCA in NAFLD patients with compensated cirrhosis is also currently underway (NCT03439254). The main goal of this trial is to determine whether OCA can improve liver histology in a patient with compensated cirrhosis as a result of NAFLD.

Several selective nonbile acid FXR agonists, hopefully without the adverse effects on lipoproteins, are being evaluated for the treatment of NAFLD (Table 2). Gilead recently presented the clinical trial data of GS-9674 in NAFLD at The Liver Meeting ${ }^{\circledR}$ 2018. In this study, patients were ran- domized to GS-9674 $100 \mathrm{mg}$, GS-9674 $30 \mathrm{mg}$, or placebo once daily for 24 weeks. Results showed that $38.9 \%$ of patients treated with GS-9674 $100 \mathrm{mg}(p=0.011 \mathrm{vs}$. placebo), $14 \%$ treated with GS-9674 $30 \mathrm{mg}(p=0.87)$, and $12.5 \%$ with placebo had a reduction in hepatic fat by at least 30 percent. There were also improvements in liver biochemistry tests and a reduction in bile acid synthesis in the $30 \mathrm{mg}$ and $100 \mathrm{mg}$ arms compared with the placebo (NCT02854605). A separate phase 2 study is examining GS-9674, selonsertib, and GS-0976 alone or in combination, in NAFLD patients with advanced fibrosis (NCT02781584). Two more FXR agonists, LMB763 (NCT02913105) and LJN452 (NCT02855164), are also under clinical investigation to test their effects on safety, tolerability, and liver inflammation in patients with NAFLD.

\section{Conclusion}

NAFLD is an underlying disease for cirrhosis and hepatocellular carcinoma and a risk factor for the development of other diseases such as metabolic syndrome, cardiovascular diseases, and type 2 diabetes. There is a growing body of literature documenting the role of dysbiosis in the pathogenesis of NAFLD. Dysbiosis also disrupts homeostasis of bile acids and affects bile acid pool size and composition [116]. Primary bile acids are converted to secondary bile acids via gut microbiota. In addition to facilitate the absorption of lipids and fatsoluble vitamins, bile acids are also signaling molecules in 
hepatic and extrahepatic tissues to modulate lipid and carbohydrate metabolism and maintain energy homeostasis. When bound to the FXR and TGR5 receptors, bile acids increase insulin sensitivity and reduce hepatic gluconeogenesis and circulating triglycerides [53]. On the other hand, bile acids possess both direct antimicrobial effects on gut microbiota via membrane disruption and leakage of cellular contents [35] and indirect inhibitory effects on bacterial overgrowth and mucosal injury via FXR [44]. There is a suppressed bile acid signaling despite elevated levels of primary and secondary bile acids in NAFLD [17]. Modulation of bile acid signaling via bile acid receptor agonists inhibits bile acid biosynthesis [117], alleviates metabolic syndromes [100], ameliorates dysbiosis [47], and improves the histology of NAFLD [99]. Although preclinical and clinical studies have demonstrated that bile acid receptor agonists such as OCA are promising strategies for NAFLD, there are still many challenges to overcome such as FXR/TGR5 selectivity, tissue selectivity, and unwanted metabolic side effects. Further clinical trials with larger sample sizes, long-term safety, and efficacy data generated from improvement in liver histology are warranted.

\section{Additional Points}

Guarantor of the article. Chunpeng Zhu is the guarantor of the article.

\section{Conflicts of Interest}

The authors declare that they have no conflicts of interest.

\section{Authors' Contributions}

All authors wrote, revised, and approved the final version of the article. Caihua Wang and Chunpeng Zhu contributed equally to this work.

\section{Acknowledgments}

This work was supported by research grants from the China Natural Science Foundation projects (81602516).

\section{References}

[1] Z. M. Younossi, A. B. Koenig, D. Abdelatif, Y. Fazel, L. Henry, and M. Wymer, "Global epidemiology of nonalcoholic fatty liver disease-meta-analytic assessment of prevalence, incidence, and outcomes," Hepatology, vol. 64, no. 1, pp. 73-84, 2016.

[2] E. M. Brunt, V. W. S. Wong, V. Nobili et al., "Nonalcoholic fatty liver disease," Nature Reviews Disease Primers, vol. 1, no. 1, article 15080, 2015.

[3] J. J. Pan and M. B. Fallon, "Gender and racial differences in nonalcoholic fatty liver disease," World Journal of Hepatology, vol. 6, no. 5, pp. 274-283, 2014.

[4] E. K. Spengler and R. Loomba, "Recommendations for diagnosis, referral for liver biopsy, and treatment of nonalcoholic fatty liver disease and nonalcoholic steatohepatitis," Mayo Clinic Proceedings, vol. 90, no. 9, pp. 1233-1246, 2015.
[5] L. A. Adams, Q. M. Anstee, H. Tilg, and G. Targher, "Nonalcoholic fatty liver disease and its relationship with cardiovascular disease and other extrahepatic diseases," Gut, vol. 66, no. 6, pp. 1138-1153, 2017.

[6] C. Sanna, C. Rosso, M. Marietti, and E. Bugianesi, "Non-alcoholic fatty liver disease and extra-hepatic cancers," International Journal of Molecular Sciences, vol. 17, no. 5, p. 717, 2016.

[7] B. Schnabl and D. A. Brenner, "Interactions between the intestinal microbiome and liver diseases," Gastroenterology, vol. 146, no. 6, pp. 1513-1524, 2014.

[8] F. Guarner and J. R. Malagelada, "Gut flora in health and disease," Lancet, vol. 361, no. 9356, pp. 512-519, 2003.

[9] S. R. Gill, M. Pop, R. T. DeBoy et al., "Metagenomic analysis of the human distal gut microbiome," Science, vol. 312, no. 5778, pp. 1355-1359, 2006.

[10] C. Petersen and J. L. Round, "Defining dysbiosis and its influence on host immunity and disease," Cellular Microbiology, vol. 16, no. 7, pp. 1024-1033, 2014.

[11] T. Ikegami and A. Honda, "Reciprocal interactions between bile acids and gut microbiota in human liver diseases," Hepatology Research, vol. 48, no. 1, pp. 15-27, 2018.

[12] A. F. Hofmann, "The function of bile salts in fat absorption. The solvent properties of dilute micellar solutions of conjugated bile salts," Biochemical Journal, vol. 89, no. 1, pp. 5768, 1963.

[13] M. D. Chow, Y. H. Lee, and G. L. Guo, "The role of bile acids in nonalcoholic fatty liver disease and nonalcoholic steatohepatitis," Molecular Aspects of Medicine, vol. 56, pp. 34-44, 2017.

[14] J. Y. L. Chiang, "Bile acids: regulation of synthesis," Journal of Lipid Research, vol. 50, no. 10, pp. 1955-1966, 2009.

[15] O. Chavez-Talavera, A. Tailleux, P. Lefebvre, and B. Staels, "Bile acid control of metabolism and inflammation in obesity, type 2 diabetes, dyslipidemia, and nonalcoholic fatty liver disease," Gastroenterology, vol. 152, no. 7, pp. 1679-1694.e3, 2017.

[16] J. M. Ridlon, D. J. Kang, and P. B. Hylemon, "Bile salt biotransformations by human intestinal bacteria," Journal of Lipid Research, vol. 47, no. 2, pp. 241-259, 2006.

[17] N. Jiao, S. S. Baker, A. Chapa-Rodriguez et al., "Suppressed hepatic bile acid signalling despite elevated production of primary and secondary bile acids in NAFLD," Gut, vol. 67, no. 10, pp. 1881-1891, 2018.

[18] J. F. Pierre, K. B. Martinez, H. Ye et al., "Activation of bile acid signaling improves metabolic phenotypes in high-fat diet-induced obese mice," American Journal of Physiology. Gastrointestinal and Liver Physiology, vol. 311, no. 2, pp. G286-G304, 2016.

[19] P. B. Eckburg, E. M. Bik, C. N. Bernstein et al., "Diversity of the human intestinal microbial flora," Science, vol. 308, no. 5728, pp. 1635-1638, 2005.

[20] P. Louis and H. J. Flint, "Diversity, metabolism and microbial ecology of butyrate-producing bacteria from the human large intestine," FEMS Microbiology Letters, vol. 294, no. 1, pp. 1-8, 2009.

[21] H. J. Flint, K. P. Scott, S. H. Duncan, P. Louis, and E. Forano, "Microbial degradation of complex carbohydrates in the gut," Gut Microbes, vol. 3, no. 4, pp. 289-306, 2012.

[22] I. Rowland, G. Gibson, A. Heinken et al., "Gut microbiota functions: metabolism of nutrients and other food 
components," European Journal of Nutrition, vol. 57, no. 1, pp. 1-24, 2018.

[23] J. L. Popp, C. Berliner, and R. Bentley, "Vitamin K (menaquinone) biosynthesis in bacteria: high-performance liquid chromatographic assay of the overall synthesis of o-succinylbenzoic acid and of 2-succinyl-6-hydroxy-2,4cyclohexadiene-1-carboxylic acid synthase," Analytical Biochemistry, vol. 178, no. 2, pp. 306-310, 1989.

[24] P. J. Turnbaugh, R. E. Ley, M. A. Mahowald, V. Magrini, E. R. Mardis, and J. I. Gordon, "An obesity-associated gut microbiome with increased capacity for energy harvest," Nature, vol. 444, no. 7122, pp. 1027-1031, 2006.

[25] P. J. Turnbaugh, F. Backhed, L. Fulton, and J. I. Gordon, "Diet-induced obesity is linked to marked but reversible alterations in the mouse distal gut microbiome," Cell Host \& Microbe, vol. 3, no. 4, pp. 213-223, 2008.

[26] R. E. Ley, P. J. Turnbaugh, S. Klein, and J. I. Gordon, "Microbial ecology: Human gut microbes associated with obesity," Nature, vol. 444, no. 7122, pp. 1022-1023, 2006.

[27] S. Devkota and E. B. Chang, "Interactions between diet, bile acid metabolism, gut microbiota, and inflammatory bowel diseases," Digestive Diseases, vol. 33, no. 3, pp. 351-356, 2015.

[28] J. R. Swann, E. J. Want, F. M. Geier et al., "Systemic gut microbial modulation of bile acid metabolism in host tissue compartments," Proceedings of the National Academy of Sciences of the United States of America, vol. 108, Supplement 1, pp. 4523-4530, 2011.

[29] L. Yao, S. C. Seaton, S. Ndousse-Fetter et al., "A selective gut bacterial bile salt hydrolase alters host metabolism," eLife, vol. 7, 2018.

[30] E. J. Stellwag and P. B. Hylemon, "7alpha-Dehydroxylation of cholic acid and chenodeoxycholic acid by Clostridium leptum," Journal of Lipid Research, vol. 20, no. 3, pp. 325-333, 1979.

[31] N. Studer, L. Desharnais, M. Beutler et al., "Functional intestinal bile acid $7 \alpha$-dehydroxylation by Clostridium scindens associated with protection from Clostridium difficile infection in a gnotobiotic mouse model," Frontiers in Cellular and Infection Microbiology, vol. 6, article 191, 2016.

[32] J. Y. Lee, H. Arai, Y. Nakamura, S. Fukiya, M. Wada, and A. Yokota, "Contribution of the $7 \beta$-hydroxysteroid dehydrogenase from Ruminococcus gnavus N53 to ursodeoxycholic acid formation in the human colon," Journal of Lipid Research, vol. 54, no. 11, pp. 3062-3069, 2013.

[33] J. Robben, G. Parmentier, and H. Eyssen, "Isolation of a rat intestinal Clostridium strain producing 5 alpha- and 5 betabile salt 3 alpha-sulfatase activity," Applied and Environmental Microbiology, vol. 51, no. 1, pp. 32-38, 1986.

[34] J. Robben, P. Caenepeel, J. Van Eldere, and H. Eyssen, "Effects of intestinal microbial bile salt sulfatase activity on bile salt kinetics in gnotobiotic rats," Gastroenterology, vol. 94, no. 2, pp. 494-502, 1988.

[35] T. H. Sannasiddappa, P. A. Lund, and S. R. Clarke, "In vitro antibacterial activity of unconjugated and conjugated bile salts on Staphylococcus aureus," Frontiers in Microbiology, vol. 8, article 1581, 2017.

[36] S. Devkota, Y. Wang, M. W. Musch et al., "Dietary-fatinduced taurocholic acid promotes pathobiont expansion and colitis in Il10-/- mice," Nature, vol. 487, no. 7405, pp. 104-108, 2012.
[37] G. Kakiyama, W. M. Pandak, P. M. Gillevet et al., "Modulation of the fecal bile acid profile by gut microbiota in cirrhosis," Journal of Hepatology, vol. 58, no. 5, pp. 949-955, 2013.

[38] K. B. M. S. Islam, S. Fukiya, M. Hagio et al., "Bile acid is a host factor that regulates the composition of the cecal microbiota in rats," Gastroenterology, vol. 141, no. 5, pp. 1773-1781, 2011.

[39] W. D. Clements, R. Parks, P. Erwin, M. I. Halliday, J. Barr, and B. J. Rowlands, "Role of the gut in the pathophysiology of extrahepatic biliary obstruction," Gut, vol. 39, no. 4, pp. 587-593, 1996.

[40] V. Lorenzo-Zúñiga, R. Bartolí, R. Planas et al., "Oral bile acids reduce bacterial overgrowth, bacterial translocation, and endotoxemia in cirrhotic rats," Hepatology, vol. 37, no. 3, pp. 551-557, 2003.

[41] M. Begley, C. G. M. Gahan, and C. Hill, "The interaction between bacteria and bile," FEMS Microbiology Reviews, vol. 29, no. 4, pp. 625-651, 2005.

[42] J. Y. Sung, E. A. Shaffer, and J. W. Costerton, "Antibacterial activity of bile salts against common biliary pathogens. Effects of hydrophobicity of the molecule and in the presence of phospholipids," Digestive Diseases and Sciences, vol. 38, no. 11, pp. 2104-2112, 1993.

[43] C. Bernstein, H. Bernstein, C. M. Payne, S. E. Beard, and J. Schneider, "Bile salt activation of stress response promoters in Escherichia coli," Current Microbiology, vol. 39, no. 2, pp. 68-72, 1999.

[44] T. Inagaki, A. Moschetta, Y. K. Lee et al., "Regulation of antibacterial defense in the small intestine by the nuclear bile acid receptor," Proceedings of the National Academy of Sciences of the United States of America, vol. 103, no. 10, pp. 3920-3925, 2006.

[45] X. Zheng, F. Huang, A. Zhao et al., "Bile acid is a significant host factor shaping the gut microbiome of diet-induced obese mice," BMC Biology, vol. 15, no. 1, p. 120, 2017.

[46] A. Parséus, N. Sommer, F. Sommer et al., "Microbiotainduced obesity requires farnesoid X receptor," Gut, vol. 66, no. 3, pp. 429-437, 2017.

[47] P. Pathak, C. Xie, R. G. Nichols et al., "Intestine farnesoid X receptor agonist and the gut microbiota activate G-protein bile acid receptor-1 signaling to improve metabolism," Hepatology, vol. 68, no. 4, pp. 1574-1588, 2018.

[48] J. Y. L. Chiang, "Bile acid metabolism and signaling," Comprehensive Physiology, vol. 3, no. 3, pp. 1191-1212, 2013.

[49] F. G. Schaap, M. Trauner, and P. L. M. Jansen, "Bile acid receptors as targets for drug development," Nature Reviews Gastroenterology \& Hepatology, vol. 11, no. 1, pp. 55-67, 2014.

[50] M. Watanabe, S. M. Houten, L. Wang et al., "Bile acids lower triglyceride levels via a pathway involving FXR, SHP, and SREBP-1c," The Journal of Clinical Investigation, vol. 113, no. 10, pp. 1408-1418, 2004.

[51] I. Pineda Torra, T. Claudel, C. Duval, V. Kosykh, J. C. Fruchart, and B. Staels, "Bile acids induce the expression of the human peroxisome proliferator-activated receptor alpha gene via activation of the farnesoid X receptor," Molecular Endocrinology, vol. 17, no. 2, pp. 259-272, 2003.

[52] B. Cariou, K. van Harmelen, D. Duran-Sandoval et al., "The farnesoid X receptor modulates adiposity and peripheral insulin sensitivity in mice," The Journal of Biological Chemistry, vol. 281, no. 16, pp. 11039-11049, 2006. 
[53] K. Ma, P. K. Saha, L. Chan, and D. D. Moore, "Farnesoid X receptor is essential for normal glucose homeostasis," The Journal of Clinical Investigation, vol. 116, no. 4, pp. 11021109,2006

[54] Y. Zhang, F. Y. Lee, G. Barrera et al., "Activation of the nuclear receptor FXR improves hyperglycemia and hyperlipidemia in diabetic mice," Proceedings of the National Academy of Sciences of the United States of America, vol. 103, no. 4, pp. 1006-1011, 2006.

[55] C. A. Brighton, J. Rievaj, R. E. Kuhre et al., "Bile acids trigger GLP-1 release predominantly by accessing basolaterally located G protein-coupled bile acid receptors," Endocrinology, vol. 156, no. 11, pp. 3961-3970, 2015.

[56] C. Thomas, A. Gioiello, L. Noriega et al., "TGR5-mediated bile acid sensing controls glucose homeostasis," Cell Metabolism, vol. 10, no. 3, pp. 167-177, 2009.

[57] B. Goodwin, S. A. Jones, R. R. Price et al., "A regulatory cascade of the nuclear receptors FXR, SHP-1, and LRH-1 represses bile acid biosynthesis," Molecular Cell, vol. 6, no. 3, pp. 517-526, 2000.

[58] K. H. Song, T. Li, E. Owsley, S. Strom, and J. Y. L. Chiang, "Bile acids activate fibroblast growth factor 19 signaling in human hepatocytes to inhibit cholesterol $7 \alpha$-hydroxylase gene expression," Hepatology, vol. 49, no. 1, pp. 297-305, 2009.

[59] T. Inagaki, M. Choi, A. Moschetta et al., "Fibroblast growth factor 15 functions as an enterohepatic signal to regulate bile acid homeostasis," Cell Metabolism, vol. 2, no. 4, pp. 217-225, 2005.

[60] G. Lou, X. Ma, X. Fu et al., "GPBAR1/TGR5 mediates bile acid-induced cytokine expression in murine Kupffer cells," PLoS One, vol. 9, no. 4, article e93567, 2014.

[61] A. J. Wigg, I. C. Roberts-Thomson, R. B. Dymock, P. J. McCarthy, R. H. Grose, and A. G. Cummins, "The role of small intestinal bacterial overgrowth, intestinal permeability, endotoxaemia, and tumour necrosis factor alpha in the pathogenesis of non-alcoholic steatohepatitis," Gut, vol. 48, no. 2, pp. 206-211, 2001.

[62] M. Mouzaki, E. M. Comelli, B. M. Arendt et al., "Intestinal microbiota in patients with nonalcoholic fatty liver disease," Hepatology, vol. 58, no. 1, pp. 120-127, 2013.

[63] V. W. S. Wong, C. H. Tse, T. T. Y. Lam et al., "Molecular characterization of the fecal microbiota in patients with nonalcoholic steatohepatitis - a longitudinal study," PLoS One, vol. 8, no. 4, article e62885, 2013.

[64] M. Raman, I. Ahmed, P. M. Gillevet et al., "Fecal microbiome and volatile organic compound metabolome in obese humans with nonalcoholic fatty liver disease," Clinical Gastroenterology and Hepatology, vol. 11, no. 7, pp. 868-875.e3, 2013.

[65] L. Zhu, S. S. Baker, C. Gill et al., "Characterization of gut microbiomes in nonalcoholic steatohepatitis (NASH) patients: a connection between endogenous alcohol and NASH," Hepatology, vol. 57, no. 2, pp. 601-609, 2013.

[66] F. Del Chierico, V. Nobili, P. Vernocchi et al., "Gut microbiota profiling of pediatric nonalcoholic fatty liver disease and obese patients unveiled by an integrated meta-omicsbased approach," Hepatology, vol. 65, no. 2, pp. 451-464, 2017.

[67] V. K. Ridaura, J. J. Faith, F. E. Rey et al., "Gut microbiota from twins discordant for obesity modulate metabolism in mice," Science, vol. 341, no. 6150, article 1241214, 2013.
[68] H. E. Da Silva, A. Teterina, E. M. Comelli et al., "Nonalcoholic fatty liver disease is associated with dysbiosis independent of body mass index and insulin resistance," Scientific Reports, vol. 8, no. 1, article 1466, 2018.

[69] T. Le Roy, M. Llopis, P. Lepage et al., "Intestinal microbiota determines development of non-alcoholic fatty liver disease in mice," Gut, vol. 62, no. 12, pp. 1787-1794, 2013.

[70] M. Mouzaki, A. Y. Wang, R. Bandsma et al., "Bile acids and dysbiosis in non-alcoholic fatty liver disease," PLoS One, vol. 11, no. 5, article e0151829, 2016.

[71] K. Nishitsuji, J. Xiao, R. Nagatomo et al., "Analysis of the gut microbiome and plasma short-chain fatty acid profiles in a spontaneous mouse model of metabolic syndrome," Scientific Reports, vol. 7, no. 1, article 15876, 2017.

[72] B. S. Samuel, A. Shaito, T. Motoike et al., "Effects of the gut microbiota on host adiposity are modulated by the shortchain fatty-acid binding $G$ protein-coupled receptor, Gpr41," Proceedings of the National Academy of Sciences of the United States of America, vol. 105, no. 43, pp. 1676716772, 2008.

[73] D. Ulluwishewa, R. C. Anderson, W. C. McNabb, P. J. Moughan, J. M. Wells, and N. C. Roy, "Regulation of tight junction permeability by intestinal bacteria and dietary components," The Journal of Nutrition, vol. 141, no. 5, pp. 769776, 2011.

[74] I. Pierantonelli, C. Rychlicki, L. Agostinelli et al., "Lack of NLRP3-inflammasome leads to gut-liver axis derangement, gut dysbiosis and a worsened phenotype in a mouse model of NAFLD," Scientific Reports, vol. 7, no. 1, article 12200, 2017.

[75] L. Miele, V. Valenza, G. la Torre et al., "Increased intestinal permeability and tight junction alterations in nonalcoholic fatty liver disease," Hepatology, vol. 49, no. 6, pp. 18771887, 2009.

[76] P. Brun, I. Castagliuolo, V. D. Leo et al., "Increased intestinal permeability in obese mice: new evidence in the pathogenesis of nonalcoholic steatohepatitis," American Journal of Physiology-Gastrointestinal and Liver Physiology, vol. 292, no. 2, pp. G518-G525, 2007.

[77] N. N. Kuzmich, K. V. Sivak, V. N. Chubarev, Y. B. Porozov, T. N. Savateeva-Lyubimova, and F. Peri, "TLR4 signaling pathway modulators as potential therapeutics in inflammation and sepsis," Vaccines, vol. 5, no. 4, p. 34, 2017.

[78] P. D. Cani, J. Amar, M. A. Iglesias et al., "Metabolic endotoxemia initiates obesity and insulin resistance," Diabetes, vol. 56, no. 7, pp. 1761-1772, 2007.

[79] J. Henao-Mejia, E. Elinav, C. Jin et al., "Inflammasome-mediated dysbiosis regulates progression of NAFLD and obesity," Nature, vol. 482, no. 7384, pp. 179-185, 2012.

[80] S. Kapil, A. Duseja, B. K. Sharma et al., "Small intestinal bacterial overgrowth and toll-like receptor signaling in patients with non-alcoholic fatty liver disease," Journal of Gastroenterology and Hepatology, vol. 31, no. 1, pp. 213-221, 2016.

[81] U. Vespasiani-Gentilucci, S. Carotti, G. Perrone et al., "Hepatic toll-like receptor 4 expression is associated with portal inflammation and fibrosis in patients with NAFLD," Liver International, vol. 35, no. 2, pp. 569-581, 2015.

[82] V. W. S. Wong, G. L. H. Wong, H. Y. Chan et al., "Bacterial endotoxin and non-alcoholic fatty liver disease in the general population: a prospective cohort study," Alimentary Pharmacology \& Therapeutics, vol. 42, no. 6, pp. 731-740, 2015. 
[83] A. Fialho, A. Fialho, P. Thota, A. J. McCullough, and B. Shen, "Small intestinal bacterial overgrowth is associated with nonalcoholic fatty liver disease," Journal of Gastrointestinal and Liver Diseases, vol. 25, no. 2, pp. 159-165, 2016.

[84] J. M. Sabaté, P. Jouët, F. Harnois et al., "High prevalence of small intestinal bacterial overgrowth in patients with morbid obesity: a contributor to severe hepatic steatosis," Obesity Surgery, vol. 18, no. 4, pp. 371-377, 2008.

[85] A. A. Shanab, P. Scully, O. Crosbie et al., "Small intestinal bacterial overgrowth in nonalcoholic steatohepatitis: association with toll-like receptor 4 expression and plasma levels of interleukin 8," Digestive Diseases and Sciences, vol. 56, no. 5, pp. 1524-1534, 2011.

[86] O. Belei, L. Olariu, A. Dobrescu, T. Marcovici, and O. Marginean, "The relationship between non-alcoholic fatty liver disease and small intestinal bacterial overgrowth among overweight and obese children and adolescents," Journal of Pediatric Endocrinology \& Metabolism, vol. 30, no. 11, pp. 1161-1168, 2017.

[87] T. Csak, M. Ganz, J. Pespisa, K. Kodys, A. Dolganiuc, and G. Szabo, "Fatty acid and endotoxin activate inflammasomes in mouse hepatocytes that release danger signals to stimulate immune cells," Hepatology, vol. 54, no. 1, pp. 133-144, 2011.

[88] A. A. Noga and D. E. Vance, "A gender-specific role for phosphatidylethanolamine N-methyltransferase-derived phosphatidylcholine in the regulation of plasma high density and very low density lipoproteins in mice," The Journal of Biological Chemistry, vol. 278, no. 24, pp. 21851-21859, 2003.

[89] X. Xu, M. D. Gammon, S. H. Zeisel et al., "High intakes of choline and betaine reduce breast cancer mortality in a population-based study," The FASEB Journal, vol. 23, no. 11, pp. 4022-4028, 2009.

[90] Y. W. Teng, M. G. Mehedint, T. A. Garrow, and S. H. Zeisel, "Deletion of betaine-homocysteine S-methyltransferase in mice perturbs choline and 1-carbon metabolism, resulting in fatty liver and hepatocellular carcinomas," The Journal of Biological Chemistry, vol. 286, no. 42, pp. 36258-36267, 2011.

[91] M. D. Spencer, T. J. Hamp, R. W. Reid, L. M. Fischer, S. H. Zeisel, and A. A. Fodor, "Association between composition of the human gastrointestinal microbiome and development of fatty liver with choline deficiency," Gastroenterology, vol. 140, no. 3, pp. 976-986, 2011.

[92] M. E. Dumas, R. H. Barton, A. Toye et al., "Metabolic profiling reveals a contribution of gut microbiota to fatty liver phenotype in insulin-resistant mice," Proceedings of the National Academy of Sciences of the United States of America, vol. 103, no. 33, pp. 12511-12516, 2006.

[93] G. Porez, J. Prawitt, B. Gross, and B. Staels, "Bile acid receptors as targets for the treatment of dyslipidemia and cardiovascular disease," Journal of Lipid Research, vol. 53, no. 9, pp. 1723-1737, 2012.

[94] Z. X. Yang, W. Shen, and H. Sun, "Effects of nuclear receptor FXR on the regulation of liver lipid metabolism in patients with non-alcoholic fatty liver disease," Hepatology International, vol. 4, no. 4, pp. 741-748, 2010.

[95] S. Dasarathy, Y. Yang, A. J. McCullough, S. Marczewski, C. Bennett, and S. C. Kalhan, "Elevated hepatic fatty acid oxidation, high plasma fibroblast growth factor 21, and fasting bile acids in nonalcoholic steatohepatitis," European Journal of Gastroenterology \& Hepatology, vol. 23, no. 5, pp. 382388, 2011.
[96] K. K. Ryan, V. Tremaroli, C. Clemmensen et al., "FXR is a molecular target for the effects of vertical sleeve gastrectomy," Nature, vol. 509, no. 7499, pp. 183-188, 2014.

[97] B. A. Neuschwander-Tetri, R. Loomba, A. J. Sanyal et al., "Farnesoid X nuclear receptor ligand obeticholic acid for non-cirrhotic, non-alcoholic steatohepatitis (FLINT): a multicentre, randomised, placebo-controlled trial," The Lancet, vol. 385, no. 9972, pp. 956-965, 2015.

[98] R. H. McMahan, X. X. Wang, L. L. Cheng et al., "Bile acid receptor activation modulates hepatic monocyte activity and improves nonalcoholic fatty liver disease," Journal of Biological Chemistry, vol. 288, no. 17, pp. 11761-11770, 2013.

[99] J. D. Roth, M. Feigh, S. S. Veidal et al., "INT-767 improves histopathological features in a diet-induced $o b / o b$ mouse model of biopsy-confirmed non-alcoholic steatohepatitis," World Journal of Gastroenterology, vol. 24, no. 2, pp. 195210, 2018.

[100] K. Jadhav, Y. Xu, Y. Xu et al., "Reversal of metabolic disorders by pharmacological activation of bile acid receptors TGR5 and FXR," Molecular Metabolism, vol. 9, pp. 131-140, 2018.

[101] Y. B. Hu, X. Y. Liu, and W. Zhan, "Farnesoid X receptor agonist INT-767 attenuates liver steatosis and inflammation in rat model of nonalcoholic steatohepatitis," Drug Design, Development and Therapy, vol. 12, pp. 2213-2221, 2018.

[102] P. Comeglio, I. Cellai, T. Mello et al., "INT-767 prevents $\mathrm{NASH}$ and promotes visceral fat brown adipogenesis and mitochondrial function," The Journal of Endocrinology, vol. 238, no. 2, pp. 107-127, 2018.

[103] Y. Ma, Y. Huang, L. Yan, M. Gao, and D. Liu, "Synthetic FXR agonist GW4064 prevents diet-induced hepatic steatosis and insulin resistance," Pharmaceutical Research, vol. 30, no. 5, pp. 1447-1457, 2013.

[104] M. C. de Oliveira, E. H. Gilglioni, B. A. de Boer et al., "Bile acid receptor agonists INT747 and INT777 decrease oestrogen deficiency-related postmenopausal obesity and hepatic steatosis in mice," Biochimica et Biophysica Acta, vol. 1862, no. 11, pp. 2054-2062, 2016.

[105] F. Haczeyni, L. Poekes, H. Wang et al., "Obeticholic acid improves adipose morphometry and inflammation and reduces steatosis in dietary but not metabolic obesity in mice," Obesity, vol. 25, no. 1, pp. 155-165, 2017.

[106] J. T. Liles, S. Karnik, E. Hambruch et al., "FXR agonism by GS-9674 decreases steatosis and fibrosis in a murine model of NASH," Journal of Hepatology, vol. 64, no. 2, article S169, 2016Supplement, 2016.

[107] Z. Zheng, Z. Zhao, S. Li et al., "Altenusin, a nonsteroidal microbial metabolite, attenuates nonalcoholic fatty liver disease by activating the farnesoid X receptor," Molecular Pharmacology, vol. 92, no. 4, pp. 425-436, 2017.

[108] S. Zhang, J. Wang, Q. Liu, and D. C. Harnish, "Farnesoid $\mathrm{X}$ receptor agonist WAY-362450 attenuates liver inflammation and fibrosis in murine model of non-alcoholic steatohepatitis," Journal of Hepatology, vol. 51, no. 2, pp. 380-388, 2009.

[109] A. Carino, S. Cipriani, S. Marchianò et al., "BAR502, a dual FXR and GPBAR1 agonist, promotes browning of white adipose tissue and reverses liver steatosis and fibrosis," Scientific Reports, vol. 7, no. 1, article 42801, 2017.

[110] A. Carino, S. Cipriani, S. Marchianò et al., "Gpbar1 agonism promotes a Pgc- $1 \alpha$-dependent browning of white adipose tissue and energy expenditure and reverses diet-induced 
steatohepatitis in mice," Scientific Reports, vol. 7, no. 1, article 13689, 2017.

[111] L. Jin, R. Wang, Y. Zhu et al., "Selective targeting of nuclear receptor FXR by avermectin analogues with therapeutic effects on nonalcoholic fatty liver disease," Scientific Reports, vol. 5, no. 1, article 17288, 2015.

[112] K. D. Lindor, K. V. Kowdley, E. J. Heathcote et al., "Ursodeoxycholic acid for treatment of nonalcoholic steatohepatitis: results of a randomized trial," Hepatology, vol. 39, no. 3, pp. 770-778, 2004.

[113] S. Mudaliar, R. R. Henry, A. J. Sanyal et al., "Efficacy and safety of the farnesoid $\mathrm{X}$ receptor agonist obeticholic acid in patients with type 2 diabetes and nonalcoholic fatty liver disease," Gastroenterology, vol. 145, no. 3, pp. 574-582.e1, 2013.

[114] T. Gautier, W. de Haan, J. Grober et al., "Farnesoid X receptor activation increases cholesteryl ester transfer protein expression in humans and transgenic mice," Journal of Lipid Research, vol. 54, no. 8, pp. 2195-2205, 2013.

[115] Y. Xu, F. Li, M. Zalzala et al., "Farnesoid X receptor activation increases reverse cholesterol transport by modulating bile acid composition and cholesterol absorption in mice," Hepatology, vol. 64, no. 4, pp. 1072-1085, 2016.

[116] J. Chen, M. Thomsen, and L. Vitetta, "Interaction of gut microbiota with dysregulation of bile acids in the pathogenesis of nonalcoholic fatty liver disease and potential therapeutic implications of probiotics," Journal of Cellular Biochemistry, vol. 120, no. 3, pp. 2713-2720, 2019.

[117] A. Al-Khaifi, M. Rudling, and B. Angelin, "An FXR agonist reduces bile acid synthesis independently of increases in FGF19 in healthy volunteers," Gastroenterology, vol. 155, no. 4, pp. 1012-1016, 2018. 


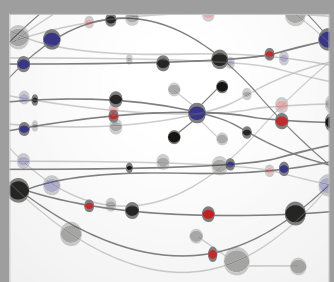

The Scientific World Journal
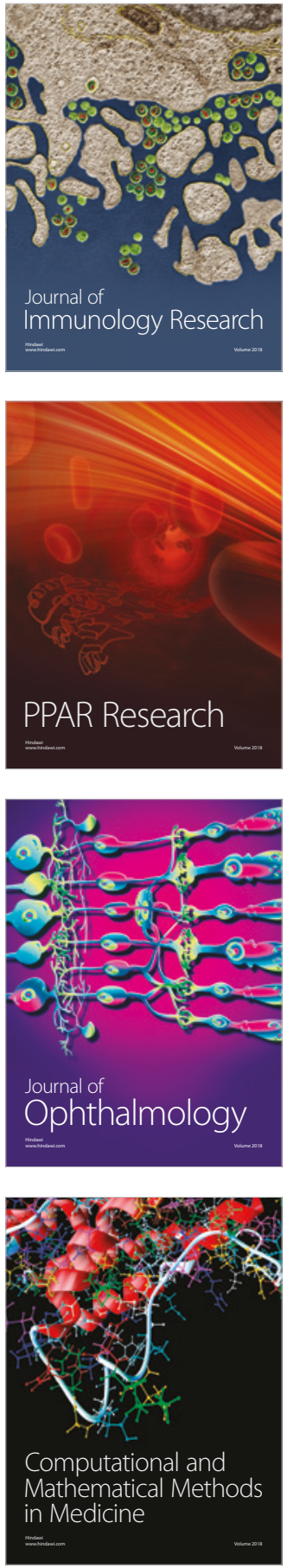

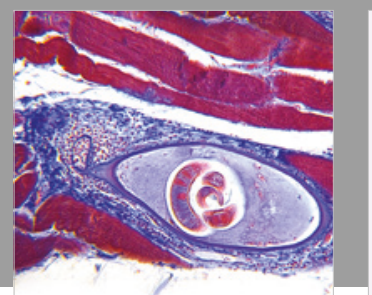

Gastroenterology Research and Practice

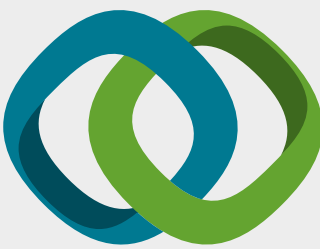

\section{Hindawi}

Submit your manuscripts at

www.hindawi.com
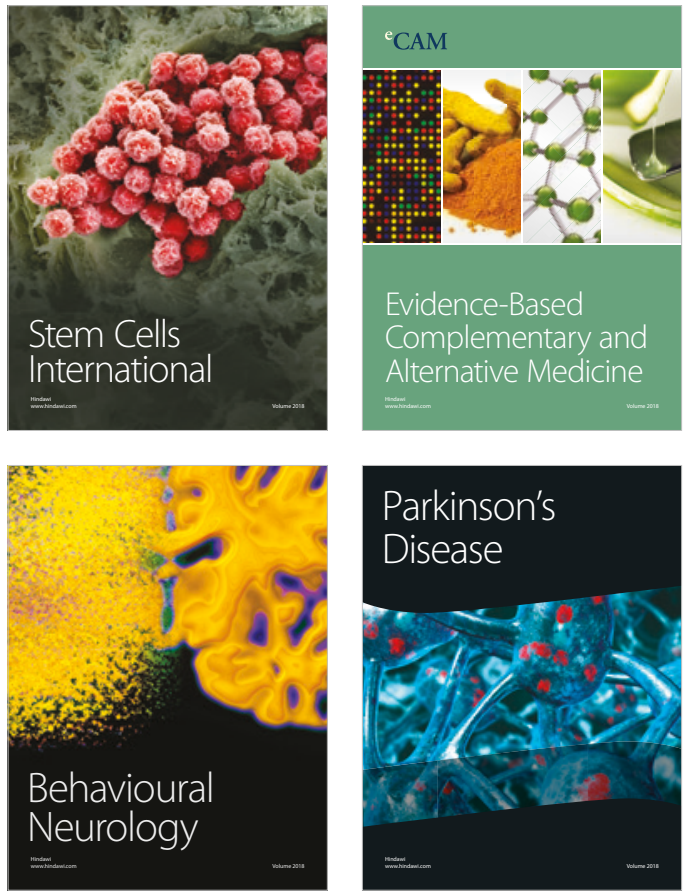

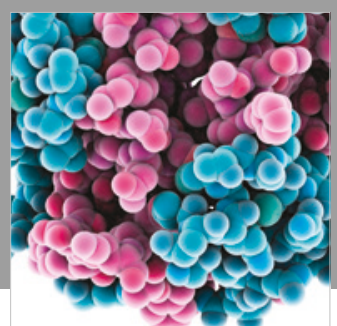

ournal of

Diabetes Research

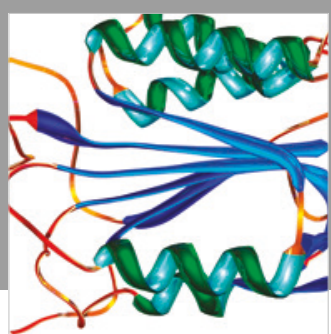

Disease Markers
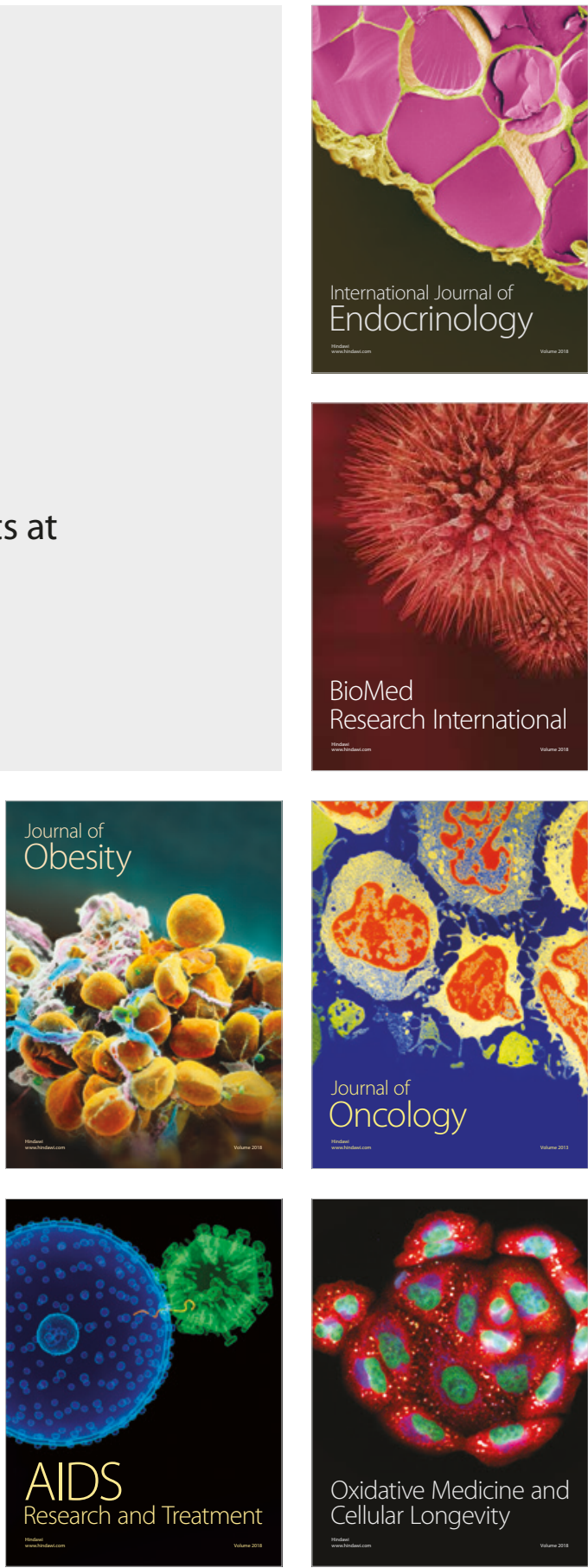